
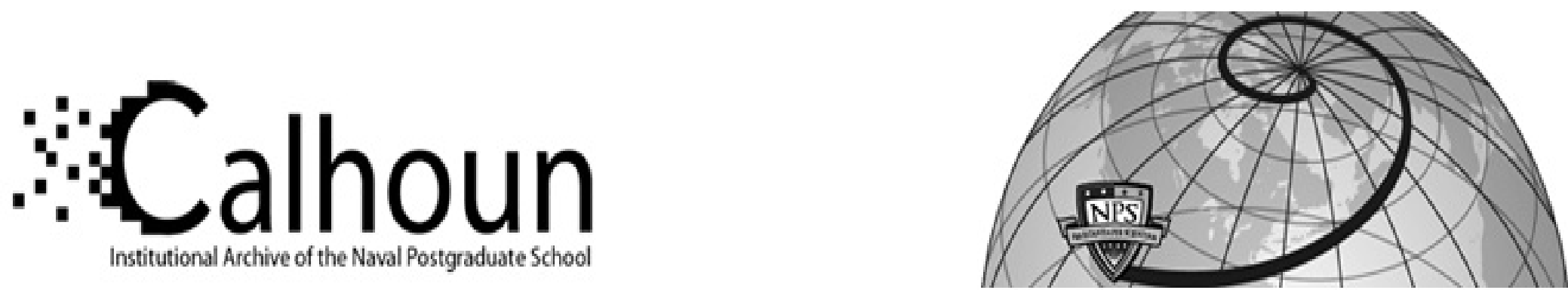

Calhoun: The NPS Institutional Archive DSpace Repository

\title{
On the Development of the Artillery Flight Characterization Electronics Rescue Kit
}

Decker, Ryan J.; Yakimenko, Oleg A.; Hollis, Michael S.; Sweeney, Patrick J.

Decker, R.J., Yakimenko, O.A., Hollis, M.S., and Sweeney, P.J., "On the Development of the Artillery Flight Characterization Electronics Rescue Kit," Proceedings of the 21st AIAA Aerodynamic Decelerator Systems Technology Conference, Dublin, Ireland, May 23-26, 2011

https://hdl.handle.net/10945/45465

This publication is a work of the U.S. Government as defined in Title 17, United States Code, Section 101. Copyright protection is not available for this work in the United States.

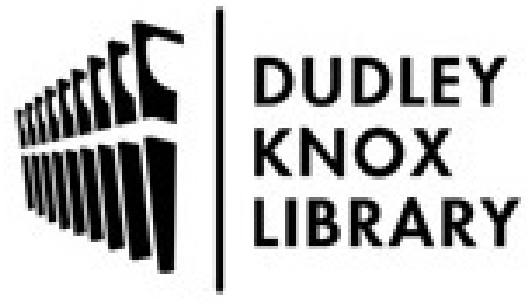

http://www.nps.edu/library
Calhoun is the Naval Postgraduate School's public access digital repository for research materials and institutional publications created by the NPS community. Calhoun is named for Professor of Mathematics Guy K. Calhoun, NPS's first appointed -- and published -- scholarly author.

Dudley Knox Library / Naval Postgraduate School 411 Dyer Road / 1 University Circle Monterey, California USA 93943 


\title{
On the Development of the Artillery Flight Characterization Electronics Rescue Kit
}

\author{
Ryan J. Decker, ${ }^{*}$ Oleg A. Yakimenko \\ Naval Postgraduate School, Monterey, CA 93943-5107 \\ Michael S. Hollis,, Patrick J. Sweeney ${ }^{\#}$ \\ Armaments Research, Development, \& Engineering Center, Picatinny Arsenal, NJ 07806-5000
}

\begin{abstract}
This paper investigates a prospective avionics suite rescue kit to salvage some of the state-of-the-art electronics in the data-collecting fuze system employed on an artillery projectile. A single-use data collection fuze is currently in use by the Army that relays sensor measurements for the purpose of characterizing the flight of an artillery projectile. The goal of the present study is to develop a parachute/parafoil-based system to be deployed automatically at apogee, so that the Reuse-Fuze $\square$ becomes separated from the body of the artillery shell and safely recovered. The paper presents the overall design of the Reuse-Fuze system, including the release mechanism, deceleration system, and impact survivability considerations. The successful design of a recoverable and reusable fuze-shaped data collection system will allow the Army to conduct repeated artillery testing without increasing the cost of expensive electronics hardware.
\end{abstract}

$\begin{array}{ll}\quad \text { Abbreviations } \\ \text { APG } & =\text { Aberdeen Proving Ground, Aberdeen, MD } \\ \text { ARDEC } & =\text { Armaments Research, Development, and Engineering Center, Picatinny Arsenal, NJ } \\ \text { ARL } & =\text { Army Research Laboratory, Aberdeen, MD } \\ \text { BRL } & =\text { Ballistic Research Laboratory, Aberdeen, MD } \\ \text { FEA } & =\text { Finite Element Analysis } \\ \text { G, n Gs } & =\text { Magnitude of earth } \ \text { gravity, number of Gs } \\ \text { NPS } & =\text { Naval Postgraduate School, Monterey, CA } \\ \text { QE } & =\text { Quadrant Elevation } \\ \text { SLIT } & =\text { Solar Likeness-Indicating Transducer }\end{array}$

I. Introduction

FLIGHT characterization testing is an important process for the Army $\sqrt{s}$ arsenal of artillery weapons. Data collected from these tests provide diagnostic information about the performance of the weapon. Using this data, current weapon systems can be improved, and future weapon systems can be engineered for better performance.

One of the current characterization systems used by the Army is a data collection fuze system that uses on-board telemetry to relay important measurements from accelerometers, solar detectors, magnetometers, and other sensors. Due to the destructive nature of an artillery shell impacting the ground, the measurement system can only be used once. A new effort is in development to attempt to salvage some of the expensive state-of-the-art electronics in the data-collecting fuze system. At apogee, the Reuse-Fuze $\square$ will become separated from the body of the artillery shell. A parachute/parafoil system will then deploy and decelerate the valuable electronics package so that when it falls to the ground it can survive a rough impact. The mechanical design effort includes the release mechanism, the deceleration system, and impact survivability of the electronics package so that it can be recovered, repackaged, and reused.

\footnotetext{
* Ph.D. Student, Department of Mechanical and Aerospace Engineering, rdecker@nps.edu, Student Member AIAA.

$\square$ Professor, Department of Systems Engineering, Code SE/Yk, oayakime@nps.edu, Associate Fellow AIAA.

Branch Chief, Structural Analysis Branch, mike.hollis1@us.army.mil.

\# Project Electrical Engineer, Telemetry Team, patrick.j.sweeney@us.army.mil.
} 
The paper is organized as follows: Section II discusses current artillery fuze data collection systems employed by test-engineers for the Army and the need for a more affordable solution. Section III discusses a new concept of a reusable fuze system and the changes that must be made to the current system to allow for recovery and reusability in terms of the two biggest design challenges: the ejection environment, and the volume restrictions of the system. Section IV provides more details on the requirements of the deceleration system to be used by the reusable fuze system, and a crushable nose to survive impact with the ground. The final section of the paper summarizes the conclusions and presents future research challenges.

\section{Current Data Collection System}

On-board data collection systems measure information about the flight of a projectile to determine important quantities such as acceleration, spin rates, and positioning. Figure 1 shows the location of the fuze on the front of an artillery projectile. A typical NATO artillery fuze system is about 5 in tall and weighs between 1.5-2.5 lbs. At the base, the fuze system has an external diameter of about 2.5 in and it tapers in a parabolic shape toward the nose. The data collection systems are designed to replicate the physical characteristics of tactical artillery fuzes so that the projectile flight dynamics represent the tactical performance of the projectile.

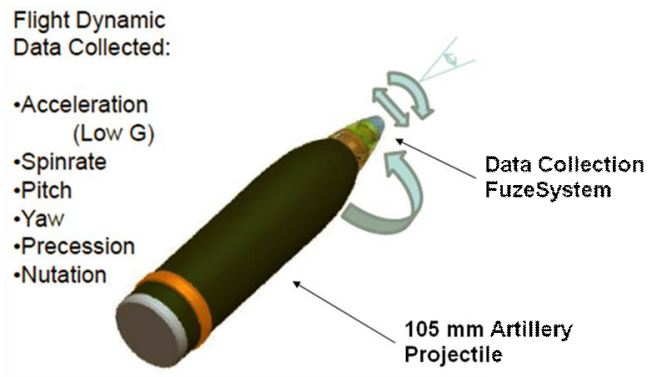

Figure 1. Fuze data collection system.

The DFuze ${ }^{1}$ version 2003 (2K3) is a technological evolution of the yawsonde $\square$ developed in the early 1970 s by both the Ballistic Research Laboratory (BRL) located at Aberdeen Proving Ground (APG), Aberdeen, MD and the Armament Research Development and Engineering Center located at Picatinny Arsenal, NJ. ${ }^{2,3}$ Fledging versions of similar telemetry systems date back to the mid 1960 $₫$ s, when during the High Altitude Research Project (HARP), the Martlet IV was designed with sun sensors to measure the second essential angle to determine vehicle attitude. ${ }^{4}$ Earlier versions included a four-channel DFuze in 1999 followed by an eight-channel version 2001. ${ }^{5}$ Both of these systems were developed by Hepner et al. at the Army Research Laboratory (ARL), APG. (BRL became part of ARL during a government laboratory realignment in 1995.)

The DFuze system is packaged inside of a NATO compatible artillery fuze body, and contains expensive electronic equipment. Its cannon-launch-qualified miniature sensors include microelectronics, on-board data acquisition, a power supply, and telemetry components necessary to obtain and transmit the desired measurements. The sensor suite within the DFuze can be configured to meet a customer $\$ \mathrm{~s}$ needs. An example configuration could consist of four solar likeness-indicating transducer (SLIT) optical sensors, ${ }^{6}$ a tri-axial magnetometer, tri-axial accelerometers for interior ballistic measurements, a ring of four radial accelerometers for drag, spin rate gyros, a temperature sensor, dual-axis rate sensors for determining body-fixed rates in the pitching and yawing planes, and four auxiliary channels for additional sensors or processor functions.

The $\square$ Aero-Fuze, $\square$ currently being developed at the Armaments Research, Development, and Engineering Center (ARDEC) at Picatinny Arsenal, NJ is intended to be an upgrade from the DFuze. The Aero-Fuze contains the same sensors as the DFuze, including a Digital Signal Processor (DSP) which allows for on-board processing of data and additional capabilities depending upon customer needs. A cross-section view and an exploded view of the current Aero-Fuze system are shown in Fig. 2. The overall hardware cost for the Aero-Fuze system is approximately $\$ 10 \mathrm{~K}$ per device plus the cost of testing personnel.

Characterization of various projectiles is becoming more of a necessity as projectiles and fuzes become more complex with electronics and processing systems. Additionally, newer propelling charges are being developed and are coming on-line. These charges have different burn rates, compared to conventional charges, and therefore change the launch characteristics of a projectile. Obtaining statistically significant flight performance data becomes an expensive endeavor. The cost of testing causes difficulty for Army program managers to decide how many devices are required for a meaningful set of test data. Since the device is destroyed upon ground impact, a new 
device is required for every shot.
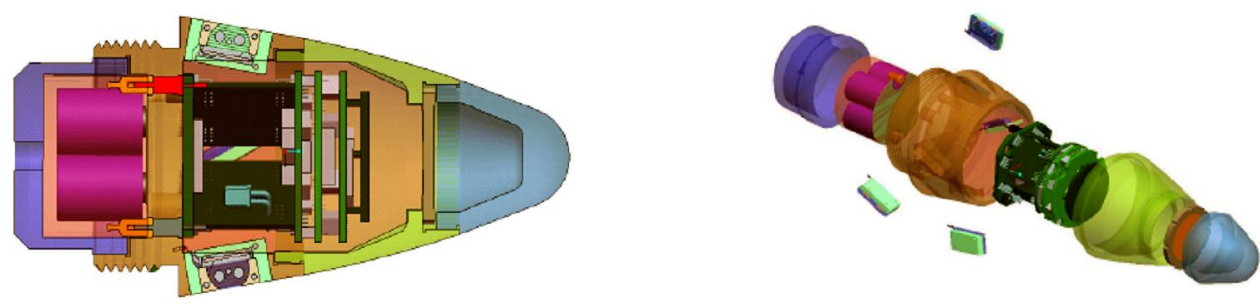

Figure 2. Current Army Aero-Fuze data collection system concept.

Often management has to choose the less expensive approach and only fires a fraction of the devices required for statistical relevance. Therefore, it is desirable to develop a system where the components can be recovered and reused. A recoverable version of the Aero-Fuze is now in development and is known as the Reuse-Fuze. The basic advantage of the recoverable version is that it releases the electronics package after the projectile has reached apogee. Being a complex problem by itself, the Reuse-Fuze will have to be expelled in the forward direction, which increases the complexity of the design and will need to incorporate the modifications discussed next.

\section{Reuse-Fuze System Overview}

The concept of releasing submunition packages from an artillery projectile in flight is not new. Several existing artillery systems have recoverable submunitions that release from the rear of the projectile. Expelling a payload from the rear is a simpler problem than forward ejection for three reasons. The first reason is that ejecting an object in the opposite direction from the projectile means that the ejected object will be traveling slower than the projectile. The second reason is that artillery projectiles have larger diameters at the rear, allowing the components responsible for ejection to occupy more volume. The final reason is that a relatively small object ejected in the forward direction may collide with the projectile.

\section{A. Deployment Conditions}

Let us consider the requirements of the deceleration system to be used in the Reuse-Fuze system. Figure 3 presents typical trajectories of a projectile launched at quadrant elevations $(\mathrm{QE})$ in the range of $50^{\circ}$ at different charge levels. (Such a QE is required for optimum performance of the SLIT sensors.) As seen from Fig. 3, using different charge levels can result in a range of apogee heights. For the purpose of ensuring a reliable design, let us choose the most conservative design parameters. This means that the deceleration system will assume that release occurs at a height of only $2,000 \mathrm{~m}$, when in reality the release is likely to occur at a higher altitude giving the deceleration system more time to slow the payload.

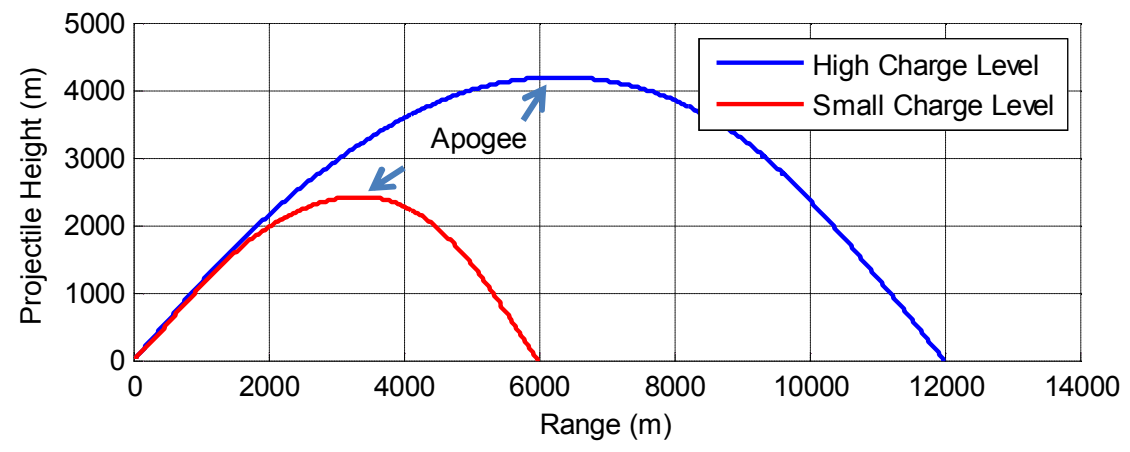

Figure 3. Example of $155 \mathrm{~mm}$ projectile trajectories at different charge levels (with $50^{\circ} \mathrm{QE}$ ).

The fuze of an artillery shell is situated at the front of the projectile and will have to be expelled in the forward direction, which increases the complexity of the design. Fortunately, when shot at a QE greater than $50^{\circ}$, an artillery projectile will have slowed to less than half of its muzzle velocity by the time it reaches apogee as shown in Fig. 4. Therefore, the conservative initial design estimates for the parachute system of the Reuse Fuze will involve decelerating the electronics package from a nearly horizontal velocity of $325 \mathrm{~m} / \mathrm{s}$ ( $30 \%$ more than a typical apogee velocity) at a minimum altitude of $2 \mathrm{~km}$. 


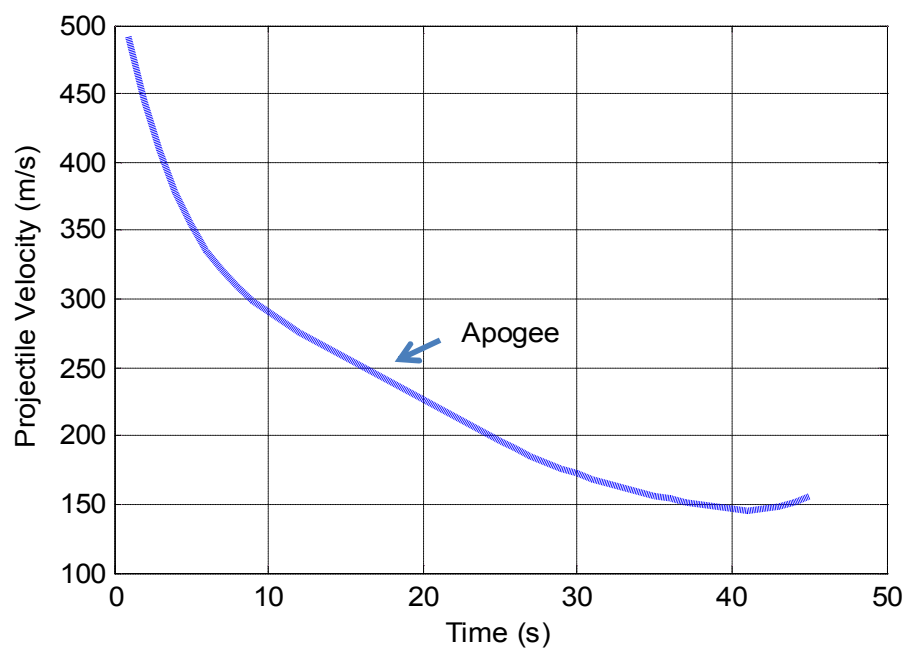

Figure 4. Typical deceleration profile of a $155 \mathrm{~mm}$ projectile.

\section{B. Design Modification Necessary for Expulsion}

A number of significant changes will have to be made to the Aero-Fuze system to allow for successful expulsion. The force required to eject the fuze from the projectile body will be delivered by an on-board explosive charge of black powder located at the rear of the data collection system. Existing artillery systems that use a rear-ejection mechanism to expel their payload (such as the $155 \mathrm{~mm} \mathrm{M} 485$ and $105 \mathrm{~mm} \mathrm{M} 314 \mathrm{~A} 3$ illumination rounds) involve the shearing of pins or threads as the release mechanism. Therefore, a radial array of shear pins, will be the initial release mechanism design for the Reuse-Fuze. For safety reasons, the black powder charge will not become armed until G-sensing switches are activated during gun launch. The ignition of the black powder charge will be triggered by two electric match squibs (for redundancy) located at the bottom of the fuze expulsion cup.

When an artillery projectile is shot from a cannon, the propelling gases cause acceleration loading known as setback. The fuze is well supported by the rim of the projectile during setback. However, during launch the projectile can experience significant angular acceleration from the gun tube rifling known as spin-up. Once the projectile leaves the muzzle, the rapid release of pressure on the base of the compressed projectile causes it to spring back to its original shape and oscillate about its center of gravity. This phenomenon is known as setforward. The effect of setforward is proportional to the distance of a component from the projectile $\$$ s center of gravity. At the front of the projectile, where the fuze is located, accelerations as high as 5,000 Gs can occur during setforward.

Since setforward and spin-up occur sequentially, they do not act as combined loading on the pins that will hold the electronics package of the data collection system to the expulsion cup of the Reuse Fuze. The principal challenge with the use of a shear pin release system is that the pins must be weak enough to break reliably during expulsion, but must be strong enough to keep the fuze system from breaking free during setforward. The calculations in Table 1 show that the shear pins must be strong enough to carry over 7,500 lb of setforward loading. This amount of force will require 8 stainless steel dowel pins (3/32 in diameter) to secure the electronics package to the expulsion cup. The values of 5,000 Gs for setforward and $440,000 \mathrm{rad} / \mathrm{s}^{2}$ are criteria used in the practice of artillery design.

For the expulsion mechanism, the black powder charge must provide enough force to reliably shear all of the pins and overcome the pressure forces acting on the front of the fuze. The total force required will be the sum of the force to break all shear pins, the force to overcome drag, and the dynamic forces on the front of the fuze. The calculations in Table 2 show the amount of pressure it will take to reliably eject the electronics package at an estimated velocity of $325 \mathrm{~m} / \mathrm{s}$ during expulsion.

Consequently, the pressure required from the black powder charge will be about 12,300 psi (with a recommended safety factor of 2). These theoretical calculations will be verified by extensive experimentation prior to testing the entire system. The image shown in Fig. 5 gives a rough idea of the overall system geometry (excluding the batteries). As shown, the expulsion charge will be located behind the drag device of the system.

\section{Aerodynamic Deceleration System}

Let us now specifically address the challenges in developing the aerodynamic deceleration system for the ReuseFuze system. 


\section{A. Ejection Environment}

There are two significant challenges with the design of the deceleration system. The primary challenge is the environment of the ejection. The expelled fuze electronics package may be traveling at a velocity of $325 \mathrm{~m} / \mathrm{s}$, which is very close to the transonic aerodynamic region. Whereas many parachute and parafoil systems used in other applications use plastic materials and nylon risers, artillery parachutes require tougher materials such as Kevlar. Some precision-guided artillery projectiles are fin-stabilized, but most of the basic rounds are spin-stabilized. At the time of ejection, the system may be spinning at an angular velocity of $200 \mathrm{~Hz}$ (revolutions per second).

Table 1. Load on Shear Pins During Launch

\begin{tabular}{|c|c|c|c|c|}
\hline Spinup Loading & \multicolumn{2}{|c|}{ English Units } & \multicolumn{2}{|c|}{ Metric Units } \\
\hline Moment of Inertia on Fuze Axis & 0.9375 & $\mathrm{Ibm}^{*} \mathrm{in}^{\wedge} 2$ & 0.00027 & $\mathrm{~kg} * \mathrm{~m}^{\wedge} 2$ \\
\hline Peak In-Bore Radial Accceleration & 440000 & $\mathrm{rad} / \mathrm{s}^{\wedge} 2$ & 440000 & $\mathrm{rad} / \mathrm{s}^{\wedge} 2$ \\
\hline Peak In-Bore Torque & 1068 & in*Ibf & 120.6 & $\mathrm{~N} * \mathrm{~m}$ \\
\hline Radius of Shear Pins & 0.75 & in & 1.91 & $\mathrm{~cm}$ \\
\hline Peak Spinup Loading & 1423 & Ibf & 6331 & $\mathrm{~N}$ \\
\hline \multicolumn{5}{|l|}{ Setforward Loading } \\
\hline Mass of Components in Setforward & 1.503 & $\mathrm{Ib}$ & 0.682 & $\mathrm{~kg}$ \\
\hline Peak Setforward Acceleration & 5000 & Gs (Ibf/lb) & 5000 & Gs \\
\hline Total Force of Setforward & 7515 & Ibf & 33427 & $\mathrm{~N}$ \\
\hline
\end{tabular}

Table 2. Expulsion Charge

\begin{tabular}{|c|c|c|c|c|}
\hline Pressure Calculations & English & Units & Metr & ic Units \\
\hline Atmospheric Pressure @ 2km & 11.76 & psi & 81.1 & $\mathrm{kPa}$ \\
\hline Force of Static Pressure & 54.1 & Ibf & 241 & $N$ \\
\hline Force of Dynamic Pressure & 84.6 & Ibf & 376 & $\mathrm{~N}$ \\
\hline Min. Force to Break 4 Shear Pins & 8000 & Ibf & 35600 & $N$ \\
\hline Minimum Total Force Required & 8139 & Ibf & 36217 & $\mathrm{~N}$ \\
\hline Area Subject to Expulsion Charge & 1.33 & in^2 & 0.00086 & $m^{\wedge} 2$ \\
\hline Minimum Propelling Pressure & 6132 & psi & 42276 & $\mathrm{kPa}$ \\
\hline \multicolumn{5}{|l|}{ Assume a Safety Factor of 2: } \\
\hline Peak Pressure of Expulsion Charge & 12263 & psi & 84552 & $\mathrm{KPa}$ \\
\hline
\end{tabular}

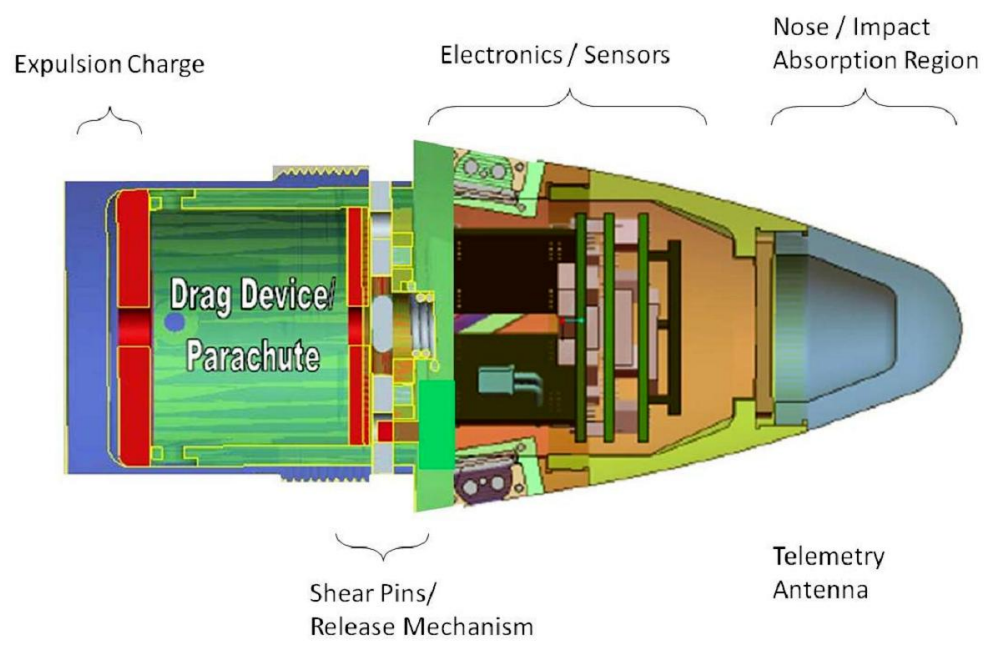

Figure 5. Preliminary system geometry.

\section{Aerodynamic Deceleration System}

Let us now specifically address the challenges in developing the aerodynamic deceleration system for the ReuseFuze system.

\section{A. Ejection Environment}

There are two significant challenges with the design of the deceleration system. The primary challenge is the environment of the ejection. The expelled fuze electronics package may be traveling at a velocity of $325 \mathrm{~m} / \mathrm{s}$, which is very close to the transonic aerodynamic region. Whereas many parachute and parafoil systems used in other applications use plastic materials and nylon risers, artillery parachutes require tougher materials such as Kevlar. Some precision-guided artillery projectiles are fin-stabilized, but most of the basic rounds are spin-stabilized. At the time of ejection, the system may be spinning at an angular velocity of $200 \mathrm{~Hz}$ (revolutions per second).

To ensure that the deceleration system can survive at such high spin rates, testing was conducted at the Precision Armaments Laboratory at Picatinny Arsenal in April, 2009. Figure 6a shows a fuze mass-simulator spin-testing system that was used to qualify different deceleration systems in terms of their ability to function at the required projectile spin rates. In these tests, a swivel device capable of tensile loads as high as $300 \mathrm{lb}$ was used to allow the 
parachute risers to resist becoming tangled. Once the systems reached the desired spin rate, they were manually ejected, allowing the deceleration systems to deploy as the payloads fell to the ground from a $220 \mathrm{ft}$ tower. These test proved that for the parachutes tested, the deceleration systems could still function when connected to a fuze spinning at $200 \mathrm{~Hz}$.

The second challenge involves the tradeoff between the size of the parachute system used for deceleration and the available volume in the fuze system. The ejection system, release mechanism, system batteries, and deceleration system must all fit within a 1.5 in diameter cylinder that will be only a few inches tall. As the height of this cylinder increases to accommodate expulsion components, the likelihood that the fuze will interfere with components of the artillery shell increases. If the Reuse-Fuze geometry penetrates too far into the fuze well of the artillery shell, it may not be an option for testing certain artillery systems. The parachute system shown in Fig. $6 \mathrm{~b}$ is a drogue parachute that is currently used on an Army mortar system. The drogue parachute is equipped with Kevlar risers which should improve the survivability of the parachute at high velocities, and can be packed to a volume smaller than $1 \mathrm{in}^{3}$.

a)

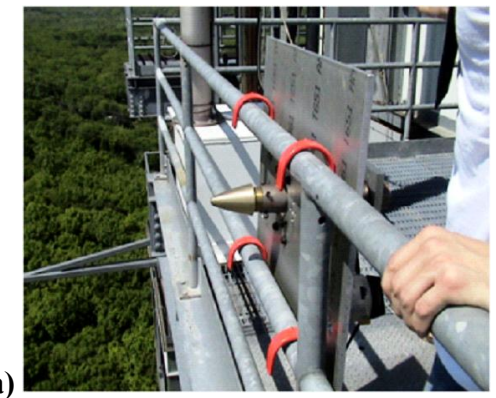

b)

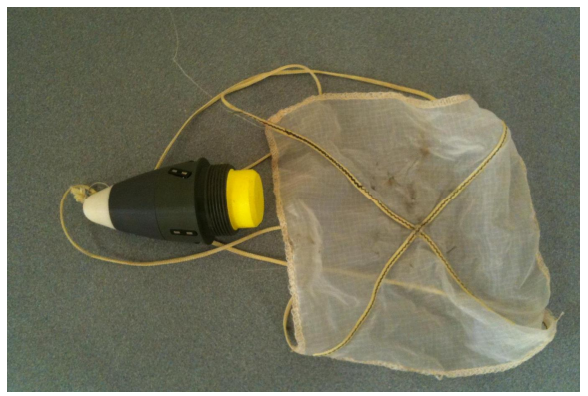

Figure 6. Spinning ejection test system at Picatinny Arsenal (a) and a drogue parachute (b).

To simulate the expected deceleration profile, a second order drag model ${ }^{7}$ was implemented in MATLAB software v7.11.0. The simulation used a fuze mass of $1.5 \mathrm{lbs}$, a conservative drag coefficient of 0.35 (based on the geometry of a blunted bullet), and a presented area of $4.7 \mathrm{in}^{2}$. For the drogue parachute shown in Fig. $6 \mathrm{~b}$, an estimated presented area of $33.2 \mathrm{in}^{2}$ was used. According to simulation estimates, the fuze electronics package slows to within $5 \%$ of its terminal velocity before it drops $500 \mathrm{~m}$ in altitude when equipped with the drogue parachute. This means that it will be safe to eject the fuze after apogee, significantly increasing the ejection timing margin. Once the terminal velocity is reached, the fuze electronics package will be traveling less than $58 \mathrm{mph}$. The predicted deceleration profiles from the MATLAB simulations are shown in Fig. 7.

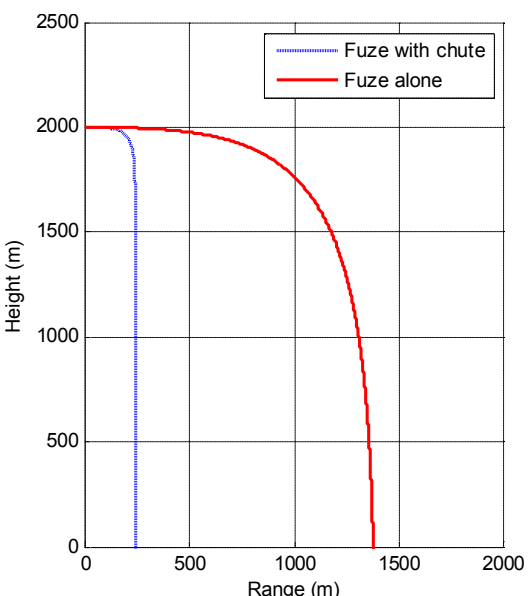

a)

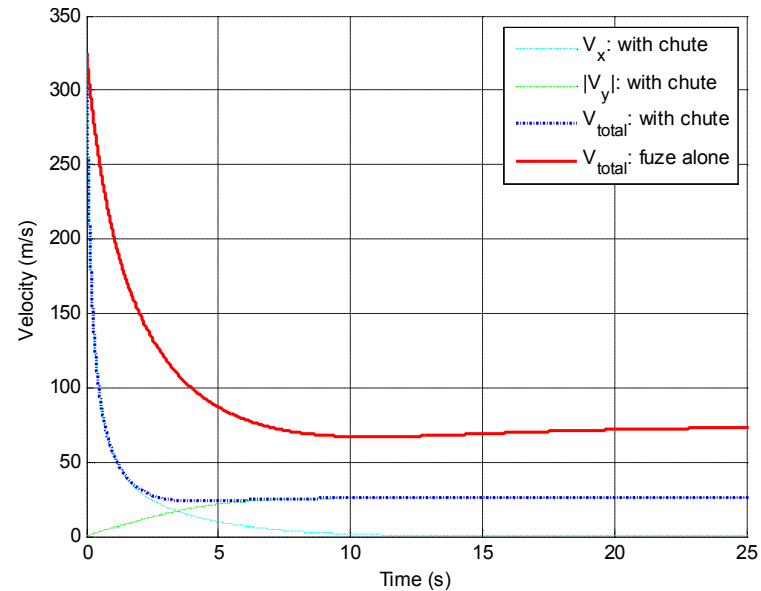

b)

Figure 7. Fuze trajectory after expulsion (a) and deceleration profile (b).

\section{B. Surviving Impact}

Another feature of the parachute deceleration system is the ability to control the impact orientation of the electronics package when it hits the ground. A $40 \mathrm{~mm}$ sensor grenade system, developed at ARDEC, is of similar shape and size to a fuze. This system has been proven to protect on-board electronics during impacts into a steel plate at over $122 \mathrm{mph}$ by employing a crushable nose design made from a polycarbonate material. The 
hemispherical crushable nose of the sensor grenade absorbs some of the deceleration energy during impact. The goal of the design is to keep the peak deceleration below $22,500 \mathrm{Gs}$, the level at which many electronic components have been demonstrated to fail in other testing. ${ }^{8}$ Figure 8 shows a Finite Element Analysis (FEA) model of a parabolicshaped version of the hemispherical design in use in the sensor grenade system that will be used to cushion the impact of the Reuse-Fuze.

Although the fuze will have more than twice the mass of the sensor grenade system, it will be moving at a lower velocity. If the deceleration system works, the kinetic energy of the fuze at impact will be about $83 \%$ of the kinetic energy of the sensor grenade system. In addition, it is likely that the fuze hitting the ground will be a softer impact than the steel plate impact assumed for the sensor grenade. Through a complete FEA model optimization, the geometry of the fuze nose will be determined to reduce the peak acceleration. Through experimentation it will be determined if the same material can be used for both systems, but it is likely that a plastic with a higher melting temperature will be required for surviving a cannon launch.

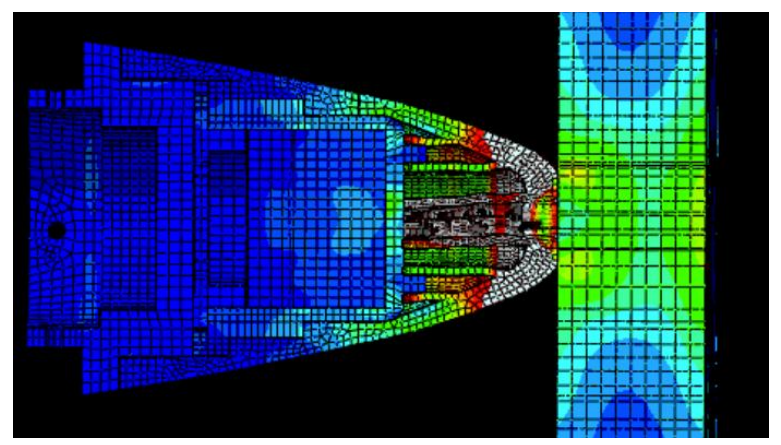

Figure 8. The FEA model of crushable nose design on Reuse-Fuze.

\section{Conclusions and Future Work}

As shown in this paper, the development of a reusable fuze-shaped data collection system for artillery projectiles is a challenging project, especially since a standard NATO fuze body is very small, and the system will need to be extremely compact to function as desired. However, such a system should significantly lower the cost of flight characterization testing. Future research will be devoted to two specific areas.

For further research, a tradeoff study of how much volume can be saved by using a mechanical release mechanism instead of shear pins, so that a smaller (and safer) expulsion charge will be conducted. (As shown over $95 \%$ of the ejection force in the Reuse-Fuze is used to break the shear pins that will hold the electronics package to the fuze expulsion cup). Such a mechanism may look like the spring-loaded cam system shown in Fig. 9. An additional benefit of using a mechanical release system is that the entire fuze electronics suite could then be recovered, repackaged, and easily re-inserted into another projectile. This would further reduce the cost of a single system by reducing the amount of disposed parts and decreasing assembly time.

Second, the authors intend to look into the possibility of using a miniature steerable parafoil system rather than just a drag chute. The reason for this is that a completely reusable system should also have the ability to be easily located once it falls to the ground. The easiest solution would be the usage of a tracking system. However, it might be desired to develop an autonomous system, in which the expelled electronics package will use an inexpensive miniature guidance, navigation, and control unit to maneuver a parafoil to a specified location. The progress in developing such systems, like Mosquito ${ }^{9}$ and Snowflake, ${ }^{10}$ as well as further miniaturizatuion of sensors and avionics, provide firm grounds to believe that artillery submunitions may have the capability to not only expel a payload, but may even enable the delivery of the payload to the specified safe location.

\section{References}

${ }^{1}$ Davis, B., Harkins, T., Hepner, D., Patton B., and Hall, R., Aeroballisitc Diagnostic Fuze (DFuze) Measurements for Projectile Development, Test, and Evaluation, $\square$ ARL-TR-3204, July 2004.

${ }^{2}$ Clay, W., $\sqsubset$ A Precision Yawsonde Calibration Technique, $\square$ BRL-MR-2263, January 1973. 
${ }^{3}$ Mermagen, W., and Clay, W., The Design of a Second Generation Yawsonde, $\square$ BRL-MR-2368, April 1974.

${ }^{4}$ Bull, G.V., and Murphy, C.H., Paris Kanonen-the Paris Guns (Wilhelmgeschutze) and Project HARP $\square$ pp.220222, 1988 Verlag.

${ }^{5}$ Hepner, D., et al., $\sqsubset$ Aeroballistic Diagnostic System, $\square$ U.S. Patent 6,349,652, February 2000.

${ }^{6}$ Hepner, D., and Hollis, M., G-Hardened Optical Alignment Sensor, $\square$ U.S. Patent 5,909,275, June 1999.

${ }^{7}$ Carlucci, D., and Jacobsen, S., Ballistics, Theory and Design of Guns and Ammunition, CRC Press, 2008, pp.169-305.

${ }^{8}$ Carlucci, P., Haynes, A.S., and Mellini, M.A., Impact Analysis and Dynamic Response of a 40mm Sensor Grenade, $\square$ Proceedings of the SIMULIA Customer Conference, ARDEC, Picatinny Arsenal, NJ, 2009.

${ }^{9} \mathrm{MJU}$ Counter Measures Sized Delivery System, URL: http://www.stara.biz/products/mosquito/mju/index.html [cited 07 October 2010].

${ }^{10}$ Yakimenko, O., Slegers, N., and Tiaden, R., Development and Testing of the Miniature Aerial Delivery System Snowflake, $\square$ Proceedings of the $20^{\text {th }}$ AIAA Aerodynamic Decelerator Systems Technology Conference, Seattle, WA, May 4-7, 2009. 